ed, and spoken of as being in a healthy state; so that in view of the healthy and vigorous condition of the patient for nearly nine months afterwards, the cancerous derelopment must have taken place within a very short period, not more than four wecks, probably, before death.

Finally, as regards the tubercular condition of the omentum, and peritoncal lining of the abdominal and pelvic cavitics, as noticed in the previous opcration, it was now found to have entirely disappeared. In neither of these cavities could the slightest trace of tubercular or other morbid change be found, save in the single organ in question.

\title{
CASE OF NEPHRITIC CALCULUS LODGED IN THE RIGHT URETER.
}

[Read before the Middlesexi East District Mledical Society, Jan. 20th, 1864, and communicated for the Boston Medical and Surgical Journal.]

By Ephrata Cutter, M.D., of Womern.

Mrs. Eustis Cummings, 28 years of agc, sanguine tempcrament, expected to be confined with her fifth child Dec. 21 st, 1863 . She was a small, healthy and symmetrical woman.

Nov. 18th, 1863, she sent for me, supposing that she was in labor. Her pains were intermittent, occurring once in ten or tifteen minutes, and were referred to the right lumbar region. They were not intense. The os uteri was high up, undilated, and evidently unaffected by the pains. The case was considered as a false alarm, and she was left with a few one-grain opium pills to lull off the pains till the full time. She was seen on the 19th and 21st; she had some pains, but there was no alteration in the condition of the os uteri. Her sufferings were moderate; she was able to move about, but not to leave the room. On the $23 \mathrm{~d}$, she sent down, and my father answered the call. He found her easier, examined the os uteri, told her that she was not going to be sick, and left. He was summoned again the same night, and did not find her condition much altered, but staid with her all night to pacify her friends. She complained of pain in the right hypochondrium mostly. At one time it was very severe, and only relieved by the inhalation of chloroform. She took plysic, and the bowels were frecly opened. It was considered by my father as a spurious case of labor, and the pains connected with the uterus. She continued in this half-way state until Dec. 6th, when she was delivered of a healthy, living, male child, in an easy labor. She continued to do well for seven days, when she was seized again with the old pain. Of course we looked for some other cause, but were unable to distinguish between intussusception and nepritic calculus. The means which had before succeeded were again employed. But the pains increased in severity, and had no intervals of rest. The pulse was regular, the respiration troubled, the face anxious, the bowels tender; there was tossing to and fro. 
Having taken two or three grains of solid opium, and a grain of the valerianate of morphia, without relief, she begged for chloroform, which procured the desired relief. My supply was soon exhausted, and I went home to procure more. On consultation with my father, we thought best to administer to her half a grain of the sulphate of morphia, dissolved in $\mathrm{f} 3 \mathrm{i}$. of water, by subcutaneous injection, and to continue the chloroform if necessary. The solution was introduced at the inside of the middle of the right leg, near the tibia. In a few minutes she fell aslcep, and continued all night till morning-a space of eight or nine hours-in a comatose condition; pulse normal; respiration four times a minute, decp, jerking, stertorous. The effect of the imperfect oxygenation of the blood became manifest in the leaden huc of the countenance and lividity of the lips, which by morning light were so deathly that I endeavored to counteract the poisonous effect of the medicine. After pouring from the nose of a coffee-pot about two pailsful of ice-water, she opened her eyes and manifested consciousiess. But she soon relapsed into the comatose condition, only to be roused by the cold douche. She was shaken, and marched about the apartment, and about noon fully camo out of the influence of the medicine and appeared quite comfortable. About 2, A.M., of the next day she was seized with pain in the ehest, oppression of breathing and gencral prostration, which continued until death, at about noon.

At the autopsy, made the next day, the lungs were found engorged with blood, the heart filled with clots on both sides; the right kidney was evidently twice the size of the left; the right ureter was enlarged, contorted and distended; at the kidney it was ncarly three quarters of an inch in diameter, and tapered down to the normal size at the bladder. About an inch from the bladder a calculus was found impacted in the ureter. This was in two portions, both together weighing $7 \frac{1}{2}$ grains. The upper part of the kidney was invaded by an abscess of the size of a hen's egg. The pelvis of the kidney was distended with urine and pus. There was some fatty degeneration of the kidney. Elsewhere the appearances were normal.

P. S.-Fer first experience of pain was during the previous summer. The dose of the sulphate of morphia may appear large. My father, a short time before, gave two grains of the same salt by separate injections, during the course of two hours, without perceptible effect.

\section{INDIANS OF SAN DIEGO COUNTY, CALIFORNIA.}

By Acting Asgistant Surgeon D. B. Hopfanan, U.S.A.

Tre Indians which inhalit San Dicgo County formerly evidently belonged to one tribe. The genuine name of that tribe, when the 